\title{
A Study on the Entry Strategies Related with Risk Management of Turkish Companies to the Emerging Economies
}

\author{
Duygu Anıl Keskin, Istanbul University \\ Ibrahim Anil, Marmara University \\ Cem Canel, University of North Carolina Wilmington
}

\begin{abstract}
There is a wide literature about companies' entry-modes (acquisition and greenfield) and ownership preferences (JV and WOS) that they use while investing abroad. In terms of these entry- modes, the explanation capacity of Institutional Theory, Transaction Cost Theory and Resource Dependency Theory have been measured by several studies. However, when these strategies are evaluated separately their explanation capacity decreases. Therefore, new approaches are used. One of these new approaches by Dunning states that the explanation capacity of these theories would be enhanced by integrating them. Dunning argues that these theories would be integrated by accepting that ownership advantages would be assessed as resource dependency theory, location advantages would be assessed as institutional theory and internalization advantages would be assessed as transaction cost theory. This Eclectic approach is used in this study in terms of the interactions of three different approaches.

Entry modes with multiple theories would be more effective than a single theory in order to explain the entry modes of these companies. In this study, entry strategies of Turkish companies to the Russia Federation, Balkan Countries and Central Asia are explained, compared and discussed in terms of these theories. The aim of this study is to contribute to the relevant literature by understanding which entry strategy would explain the behavior of Turkish companies while investing in other developing countries.
\end{abstract}

JEL Code: M10

\section{Theoretical Framework}

Previous studies, which are about entry and ownership modes of firms, show that the companies use four different modes in terms of their FDI. There are JV and WOS ownership mode, Greenfield and Acquisition entry mode. According to the different approaches, which are explained below, firms prefer different entry and ownership modes.

\subsection{Institutionalist Approach}

According to Gatignon and Anderson (1998, pg.315) country risks generally consist of the political, legal, cultural and economic environment of the country and there is a relationship between these factors and the stability of commercial activities. They argue that the more the risk increases the companies may choose JV because JV gives the possibility to be more flexible in risky environments. The study of Kim and Hwang (1992, pg.35) confirms those arguments by indicating that multinational companies prefer JV entry mode when country risk is high.

Another factor that leads the companies to prefer JV as an entry mode is that the cultural distance between the host country and the country of the investor company. According to several studies (Kogut and Singh, 1988; Gatignon and Anderson, 1988; Erramilli and Rao, 1993; Meyer, 2001 and Tsai and Cheng, 2004) when the cultural distance is high, investor companies prefer to enter by using JV. However, Brouthers and Brouthers (2000) report that there is not any significant relationship between cultural distance and entry mode of Japanese firms that investing in Western Europe. Finally, Anıl and Çakır (2010, pg.11-12) found out that 
when firms are fully aware of the similarities between the business styles and the local culture of the country in question, they prefer JVs. However, the study reveals no meaningful connection between the cultural similarity and the preference of entry mode (Greenfield or acquisition).

\subsection{Transaction Cost Approach}

This approach argues that the organization and the administration structure reducing the transaction costs are the key elements of entry modes of companies (Zhao et al., 2004, pg.526). When the costs of protection against opportunist behavior, performance monitoring and adaptation of production technologies are high, the firm would prefer an internal administration structure (WOS) (Luo, 2001, pg.445,. Meyer and Peng (2005, pg.603),Williamson, 1985)

Several studies in this field (e.g. Gatignon and Anderson, 1988; Padmanabhan and Cho, 1996; Delios and Beamish, 1999; Makino and Neupert, 2000; Luo, 2001; Brouthers, 2002; Tsai and Cheng, 2004) point out that when the firm's asset specificity is high, it is more likely to prefer JV rather than WOS. However, it could be said that there are some exception of this situation. For example, Padmanabhan and Cho (1996, pg.48) argue that When technological deficits in the transition economies are taken into account, an R\&D-intensive firm may prefer to have full control in order to protect its proprietary expertise and/or to use it optimally. They also report that R\&D-intensive Japanese firms generally prefer whole ownership (WOS) in their foreign investments. In addition, since in some conditions the institutional structure cannot protect the intellectual capital of firms, technology-intensive firms prefer to internalize (WOS) their transactions that requires advanced technology (Meyer 2001, pg.360).

Sometimes uncertainty plays an important role on the entry mode choosing process. Especially when uncertainty renders contracts ineffective and leads the partners to be exposed to delays, WOS is preferred (Brouthers and Hennart, 2007, pg. 403).

Transaction cost theorists report that the firm's old experience in the host country or in the international areas has a significant effect on the entry and ownership mode choosing process. In terms of this argument, firms have a significant international experience would prefer to WOS since they do not need to local partners (Dikova and Wittelloostuijn, 2007, pg.1016; Padmanabhan and Cho, 1999, pg.27; Gatignon and Anderson, 1988; Delios and Beamish, 1999; Tsai and Cheng, 2004). Firm's international experience also affects acquisition greenfield dilemma (Larimo, 2003, pg.794).

\subsection{Resource Based Approach}

According to Brouthers and Hennart (2007, pg.404) firms' organizational abilities related to the resources could be used as an advantage in the international markets. Moreover, sometimes firms want to enter international markets in order to gain some key resources. In terms of this argument it could be said that while selecting their partners firms from developing markets are more eager to share the financial assets, technical abilities, abstract assets and expertise of their partners; on the other hand, firms from developed markets emphasize the unique competence, market knowledge and access to the market of more than one partner (Hitt et.al.,2000, 461463). In addition, developed markets' firms use their own resources in order to obtain competitive advantage and they prefer to work with partners which have core competence, local market experience and opportunity for entering to the market; however, developing markets' firms search for partners which they can learn organizational and technical abilities.

Meyer et. al. (2009, pg.62) point out that firms that enter to developing economies prefer to use JV strategies when the institutional conditions of these economies are weak because they can access to important resources by using this strategy. On the other hand, when the institutions are stronger and the market activity is higher, they choose acquisition strategy.

Under the conditions that there are no local partners for the firms that need to obtain new resources in the new market, according to Anand and Delious (1997, pg.582), acquisitions are the only solution. 
When the technological abilities of a firm are treated as a resource, firms that have technological abilities would prefer to greenfield strategy for a few reasons. First of all the local firms do not have sufficient technological ability to present to firms that have stronger technological capacity. Secondly, if the acquirer has superior technological competences, transfer of these competences to the acquire company may be difficult or impossible because of the organizational inertia, i.e. the resistance of the workers within the acquired firm to the changes that would result from the acquisition process.

Finally, the size of a firm is regarded as an important antecedent of competitive advantage of the firm (Ekeledo and Sivakumar, 2004, pg.78). According to the some researcher (e.g. Buckley and Casson, 1976; Terpstra and Yu, adapted from Kumar, 1984, 1988, pg.35; Chang and Rosenzweig, 2001, pg.756) big companies are good at eliminating the risks and costs relating to foreign direct investments and have greater advantage in balancing disadvantageous positions. It is also argued that the larger the investment firm, the greater the acquisition competence of the firm (Kogut and Singh, 1988, pg.420; Larimo 2003, pg.801.)

\subsection{Eclectic Approach}

This approach, also entitled OLI (Ownership, Location, Internalization) argues that the firms choose the most convenient entry mode to the international markets and while doing that they evaluate the firms' own ownership advantages (Resourca Based Theory), host country's position (Institutional Theory), and the internalizing advantages (Transaction cost Theory) of integrating the operations within the firm (Tatoglu and Glaister, 1998, pg.284).

In their study, Agarwal and Ramaswami (1992, pg.20-21) analyze the impact of mutual mutual relations among the firm's property (ability to develop differentiated product, its magnitude and international experience), the firm's position (potential of the market and its investment risk) and the firm's internalizing advantages (risks regarding the contract) in the firm's preferred market entry modes (exportation, licensing, JV, WOS). The results of this study show that most of the small firms which are not experienced enough in international markets prefer to use JV as a entry mode because JV agreements give a chance to share the risks, the costs and also complementary assets and abilities of the partner firm. However, big firms which are already experienced enough in international markets prefer to use WOS since they want to expand markets with lower potential and realize their profit targets. In addition, according to this study when the contractual risks of the firms which have the ability developing differentiated products are considered high, firms are apt to use WOS.

According to several researchers (e.g. (Hoskisson et al., 2000; Luo, 2001; Wright et al., 2005; Meyer and Peng, 2005; Brouthers and Hennart, 2007) there are more than one factors that affect the firms' preferences in terms of entry modes especially in the developing economies and that's why it is not possible to explain firm behavior of international companies by using only one theory or approach. Under the light of this assumption it could be argued that since Dunning's Eclectic Approach covers all other theories and approaches it has a more explicative framework (Brouthers and Hennart, 2007).

At last but not least it should be noted that this theoretical framework does not consist of the differences between managers in terms of risk perception. Since the key decision makers' risk perception would alter from one person to one another it could affect the entry mode choice of firms.

\section{Findings}

The third part of questionnaire format using for Institutional Theory18 scales; of location selection factors; that was developed by Glaister and Tatoğlu (1998) was used in order to identify the realities regarding these firms, and the questionnaire was given to 107 firms and 169 facilities in 7 countries (Bulgaria, Romania, Uzbekistan, Kazakhstan, Turkmenistan, 
Kyrgyzstan and Russia). For this study one question; "to have the advantage of being the first to enter the market" was added to the questionnaire form. The fourth part of questionnaire format using for Transaction cost Theory 13 scales of internalizing advantages of integrating the operations of firms and fifth part of questionnaire format using 7 scales of ownership advantages of firms was used. The values of the criteria which were measured by the questionnaire forms according to 5-point likert scale and averages of the points were as follows;

\subsection{Findings About the Expainatory Capacity of Instutional Theory}

\subsubsection{The Relationship Between Type of Investment and Ownership Pattern with Location Selection Factors}

Our finding shows differences of nineteen location selection determinats in terms of the type of investment. It is seen that convictions about the growth rate of the economy, the degree of unionization and the purchasing powers of customers affect preferences in regard to Greenfield or acquisition. That is, there is a significant difference between two groups at the level of significance is 0.05 . Accordingly, firms who perceive "Geographical Proximity", "the growth rate of economy" and "Level of Unionization" as high prefer the greenfield investment type.

Other finding shows differences of nineteen location selection determinats in terms of the ownership patterns. There is just one significant difference in terms of the preferences about capital structure (type of ownership). It is "Level of Industry Competition" and firms who percieve it as high prefer WOS.

\subsubsection{The Relationship Between Ownership Pattern whit the Cultural Familiarity}

There is a significant difference between WOS and JV groups about "similarity level of local cultures" and "similarity level of ways of business" at 0.05 significance level. Accordingly, firms that have high levels of perception about the similarity of local cultures and similarity of ways of business prefer JV ownership. There is no significant difference between "corporate culture" and "similarity of business ethics" in terms of ownership pattern.

There is a significant difference between WOS and JV patterns in terms of newly formed variable which is derived by the means of cultural variables above. JV is preferable in high levels of cultural familiarity.

Additionally, the relationship between cultural familiarity and mode of entry is analyzed but any significant difference cannot be determined.

\subsubsection{The Relationship Between Type of Investment and Ownership Pattern on Risk Taking}

The risk-taking behavior of traditionally internationalized firms is explained by a correlation with the amount of expected inputs (Buckley and Casson, 1981; Chakrabarti, 2001). Buckley et al., (2007) verified that the phenomenon of highly risk-laden direct capital investments ventured by China is also true for the foreign investments by Turkish firms. All of the Turkish firms, except for one operating in Uzbekistan, work at high performance. It is seen that they have made their investments without considering the risk aspect (Demirbağ et al. 1998), which verifies the findings of previous studies. No correlation has been found between UNCTAD's data on the total investment countries receive and the data of the Undersecretaries of Treasury of the Turkish Republic. Same is true for risk factor data and COFACE risk index data.

Based on these results, there is no statistically significant difference was found between the averages of benefiting from economies of scale, better resource and capacity use, qualified and privileged access to inputs, presence in new markets, opportunity for rapid entry into markets, investment profitability, harmony with Turkish government policy, cost of contracting and implementation, avoiding the risk of misusing production information, ensuring sufficient quality control, insufficient legislation on patent and license rights, inability to make technology transfers through licensing and patents, and in agencies and licensing with the 
ownership pattern and type of investment. Only one relation was found implementation cost of contracts with type of investment. Firms who percieve cost of contracts as high prefer greenfields. The level of significance is 0.05 .

Those who claimed that it was unimportant expressed that they accepted the risk in order to achieve the required outcome, whereas those that regarded it as highly important said that this factor ensures a non-competitive environment and so this aspect was very important in order to sustain the same environment.

\subsection{Findings About the Expainatory capacity of Resource Based Theory}

According to our results, there is no statistically significant difference was found between the averages of International experience, Brand and product image, Practicing level of technology and managerial information, Experience in markets of the chosen country, Quality of staff improvement program, Staff quality and Product differentiation and development skills with ownership pattern and type of investment. Independent $\mathrm{T}$ tests are used to see if there is any significant difference between entry mode groups (acquisition or green field) for all items in group of ownership advantages. Only one relation was found that international experience with type of investment Results show significant difference for them. Firms who percieve their international experience as high, they prefer greenfields. The level of significance is 0.05 .

\subsection{Findings About the Expainatory capacity of Transaction Cost Theory}

Independent $\mathrm{T}$ tests are used to see if there is any significant difference between entry mode groups (acquisition or green field) for all items of internalization advantages which consist of; 4.1. benefiting from economies of scale, 4.2. better resource and capacity use, 4.3. qualified and privileged access to inputs, 4.4. presence in new markets, 4.5. opportunity for rapid entry into markets, 4.6. investment profitability, 4.7. harmony with Turkish government policy, 4.8. cost of contracting and implementation, 4.9. avoiding the risk of misusing production information, 4.10. ensuring sufficient quality control, 4.11. insufficient legislation on patent and license rights, 4.12. inability to make technology transfers through licensing and patents, 4.3. difficulties of agencies and licensing implementations. Reliability analysis is executed for this group of internalization; that consists thirteen items. Cronbach Alpha statistics is calculated as 0.7153 . These items are used for factor analysis and four factors are emerged. KMO measure of sampling adequacy is calculated as 0.6690 and explained variance is 69.5680 per cent by factors.

Group internalization results show significant difference for only cost of contracts item. Variances are assumed equal because of Levene's test and the significance level is estimated as 0.039 for mean difference. As a result, mean difference between groups is statistically significant at level 0.05 .

\subsection{Findings About the Expainatory capacity of Eclectic Theory}

Dunning's Eclectic Approach's arguments in terms of advantages that are related to the country and company it could be said that the following factors have an impact on the decision of the Turkish companies: having a factory in EU, taking the advantage of being first mover, entering international markets, buying a cheap facility in terms of privatization. Hence, in this study which tries to explain the entrance behavior of the companies from different sectors, sizes and from different entrance years, it has been found that Eclectic Approach is more exploratory than other theories. All of these conditions have an impact more or less on the decision of Turkish companies decicons. İn addition to this factors Eclectic theory has been covering other three theories via İLO approach. That means (L) location selection factors of "Geographical Proximity", "the growth rate of economy" and "Level of Unionization" firms who perceive as high prefer the greenfield investment type. There is just one significant difference in location selection factor, terms of the preferences about capital structure (type of 
ownership). It is "Level of Industry Competition" and firms who percieve it as high prefer WOS. Finally, firms that have high levels of perception about the similarity of local cultures and similarity of ways of business prefer JV ownership.

(O) Ownership factors of international experience; Firms who percieve their international experience as high, they prefer greenfields.

(I) Internalization factors of "Implementaion cost of contract" which Firms who percieve cost of contracts as high prefer greenfields.

\section{Conclusions}

This study analyzed which entry (Greenfield/ acquisition) and ownership (JV/WOS) styles are used by one developing country's firms (Turkey) during the entrance process to another developing countries. By doing that various theoretical aspects, Institutional Theory, Transaction Cost Theory, Resource Dependency Theory and Dunning's Eclectic Approach (OLI) which covers first three theories with additional factors, has been used. Despite of the wideness of research that deals with the entrance styles of the developed countries' companies and their entrance process to the developing countries, there are relatively few studies that deal with the entrance styles of developing countries' companies that enter other developing countries. Thus, this study aims to contribute filling this gap.

In this study it has been found that none of the relevant theories could explain the entrance behavior of Turkish companies alone; but, each of them partially explains it. As a result, it could be said that Dunning's Eclectic Approach is more explanatory than other theories.

Although Institutional Theory argues that in the countries where uncertainty and cultural distances are high companies would choose JV, all of the Turkish companies analyzed and has been found similar results. in this study. Moreover, these companies indicate that they did not care about the transaction costs because the conditions were similar to Turkey.

\section{References}

- Agarwal and Ramaswami.(1992).Choice of Foreign Market Entry Mode: Impact of Ownership, Location and Internalization Factors. Journal of International Business Studies. 23.1, 1-27.

- Anand and Delios. (1997). Location Specificity and The Transferability of Downstream Assets to Foreign Subsidiaries. Journal of International Business Studies. 28.3, 579-603.

- Anand and Delios. (2002). Absolute and Relative Resources as Determinants of International Acquisitions. Strategic Management Journal. 23.2, 119-134.

- An1l, Cakir and Canel. (2010). A Comparison of Inward and Outward Foreign Direct Investment Determinants in Turkey. Southeast Decision Sciences Institute Fortieth Annual Conference, Wilmington, Proceedings Book. 528-542.

- Barkema and Vermeulen. (1998). International Expansion Through Start-Up or Acquisition: A Learning Perspective. Academy of Management Journal. 41.1, 7-26.

- Brouthers,(2002). Institutional, Cultural and Transaction Cost Influences on Entry Mode Choice and Performance. Journal of International Business Studies. 33.2, 203221.

- Brouthers and Brouthers. (2000). Acquisition or Greenfield Start-Up? Institutional, Cultural and Transaction Cost Influences. Strategic Management Journal.21.1, 89-97.

- Brouthers, Brouthers and Werner. (1996). Dunning's Eclectic Theory and The Smaller Firm: The Impact of Ownership and Locational Advantages on The Choice of Entry-Modes in The Computer Software Industry. International Business Review. 5.4, 
377-394.

- Brouthers, K. D. and J. F. Hennart. (2007). Boundaries of the Firms: Insights From International Entry Mode Research. Journal of Management. 33.3, 395-425.

- Buckley, Clegg, Cross, Liu, Voss And Zheng (2007) “The Determinants of Chinese Outward Foreign Direct Investment”, Journal of International Business Studies, 38

- Chakrabarti, A. (2001), "The Determinants of Foreign Direct Investment: Sensitivity Analyses of Cross-country Regressions”, Keyklos, Vol.54

- Chang and Rosenzweig. (2001). The Choice of Entry Mode in Sequential Foreign Direct Investment. Strategic Management Journal. 22.8, 747-776.

- Delios and Beamish. (1999). Ownership Strategy of Japanese Firms: Transactional, Institutional, and Experience Influences. Strategic Management Journal. 20.10, 915933.

- Demirbag, Tatoglu and Glaister. (2008). Factors Affecting Perceptions of the Choice between Acquisition and Greenfield Entry: The Case of Western FDI in an Emerging Market. Management International Review. 48.1, 5-38.

- Dikova and Witteloostuijn. (2007). Foreign Direct Investment Mode Choice: Entry and Establishment Modes in Transition Economies. Journal of InternationalBusiness Studies. 38.6,1013-1033.

- Dunning, (1993). Multinational Enterprises and The Global Economy. Wokingham, UK: Addison-Wesley.

- Ekeledo and Sivakumar. (2004). International Market Entry Mode Strategies of Manufacturing Firms and Service Firms: A Resource-Based Perspective. International Marketing Review. 21.1, 68-101.

- Erramilli and Rao. (1993). Service Firms'International Entry-Mode Choice: A Modified Transaction-Cost Analysis Approach. Journal of Marketing. 57.3, 19-38.

- Erramilli, Agarwal and Dev. (2002). Choice Between Non-Equity Entry Modes: An Organizational Capability Perspective. Journal of International Business Studies. 33.2, 223-242.

- Gatignon and Anderson. (1988). The Multinational Corporation's Degree of Control over Foreign Subsidiaries: An Empirical Test of Transaction Cost Explanation. Journal of Law, Economics, and Organization. 4.2, 305-336.

- Hennart and Larimo. (1998). The Impact of Culture on the Strategy of Multinational Enterprises: Does National Origin Affect Ownership Decisions?. Journal of International Business Studies. 29.3, 515-538.

- Hitt, Dacin, Lewitas, Edhec and Borza. (2000). Partner Selection in Emerging and Developed Market Contexts: Resource-Based and Organizational Learning Perspectives. Academy of Management Journal. 43.3, 449-467.

- Hoskisson, Eden, Lau and Wright. (2000). Strategy in Emerging Economies. Academy of Management Journal. 43.3, 249-267.

- Kim and Hwang. (1992). Global Strategy and Multinationals' Entry Mode Choice. Journal of International Business Studies. 23.1, 29-53.

- Kogut and Singh. (1988). The Effect of National Culture on the Choice of Entry Mode. Journal of InternationalBusiness Studies. 19.3, 411-432.

- Larimo, (2003). Form of Investment by Nordic Firms in World Markets. Journal of Business Research. 56.10, 791-803.

- Luo (2001). Determinants of Entry in an Emerging Economy: A Multilevel Approach. Journal of Management Studies. 38.3, 443-472. 
- Makino and Neupert. (2000). National Culture, Transaction Costs, and the Choice Between Joint Venture and Wholly Owned Subsidiary. Journal of International Business Studies. 31.4, 705-713.

- Meyer (2001). Institutions, Transaction Costs, and Entry Mode Choice in Eastern Europe. Journal of International Business Studies. 32.2, 357-367.

- Meyer and Peng. (2005). Probing Theoretically into Central and Eastern Europe: Transactions, Resources, and Institutions. Journal of International Business Studies. 36.6, 600-621.

- Meyer, Estrin, Bhaumik and Peng. (2009). Institutions, Resources, and Entry Strategies in Emerging Economies. Strategic Management Journal. 30.1, 61-80.

- Padmanabhan, and Cho. (1996). Ownership Strategy for a Foreign Affiliate: An Empirical Investigation of Japanese Firms. Management InternationalReview. 36.1, 45-65.

- Padmanabhan and Cho. (1999). Decision Specific Experience in Foreign Ownership and Establishment Strategies: Evidence from Japanese Firms. Journal of International Business Studies. 30.1, 25-41.

- Tatoglu and Glaister. (1998). Determinants of Foreign Direct Investment in Turkey. Thunderbird International Business Review. 40.3, 279-314.

- Tsai and Cheng. (2004). Asset Specificity, Culture, Experience, Firm Size and Entry Mode Strategy: Taiwanese Manufacturing Firms in China, South-East Asia and Western Europe. International Journal of Commerce \& Management. 14.3/4, 1-27.

- Williamson, (1985). The Economic Institutions of Capitalism. New York: Basic Books.

- Wright, Filatotchev, Hoskisson and Peng. (2005). Guest Editors' Introduction: Strategy Research in Emerging Economies: Challenging the Conventional Wisdom. The Journal of Management Studies. 42.1, 1-33.

- Zhao, Luo and Suh. (2004). Transaction Cost Determinants and Ownership-Based Entry Mode Choice: A Meta-Analytical Review. Journal of International Business Studies. 35.6, 524-544 